\title{
Does shear wave ultrasound independently predict axillary lymph node metastasis in women with invasive breast cancer?
}

\author{
Andrew Evans $\cdot$ Petra Rauchhaus $\cdot$ Patsy Whelehan $\cdot$ Kim Thomson • \\ Colin A. Purdie $\cdot$ Lee B. Jordan · Caroline O. Michie • Alastair Thompson • \\ Sarah Vinnicombe
}

Received: 21 August 2013/Accepted: 21 October 2013/Published online: 4 December 2013

(C) Springer Science+Business Media New York 2013

\begin{abstract}
Shear wave elastography (SWE) shows promise as an adjunct to greyscale ultrasound examination in assessing breast masses. In breast cancer, higher lesion stiffness on SWE has been shown to be associated with features of poor prognosis. The purpose of this study was to assess whether lesion stiffness at SWE is an independent predictor of lymph node involvement. Patients with invasive breast cancer treated by primary surgery, who had undergone SWE examination were eligible. Data were retrospectively analysed from 396 consecutive patients. The mean stiffness values were obtained using the Aixplorer ${ }^{\circledR}$ ultrasound machine from SuperSonic Imagine Ltd. Measurements were taken from a region of interest positioned over the stiffest part of the abnormality. The average of the mean stiffness value obtained from each of two orthogonal image planes was used for analysis. Associations between lymph node involvement and mean lesion stiffness, invasive cancer size, histologic grade, tumour type, ER expression, HER-2 status and vascular invasion were assessed using univariate and multivariate logistic regression. At univariate analysis, invasive size, histologic grade, HER-2 status, vascular invasion, tumour type and mean stiffness were significantly associated with nodal involvement. Nodal involvement rates ranged from $7 \%$ for tumours with mean stiffness $<50 \mathrm{kPa}$ to $41 \%$ for tumours
\end{abstract}

A. Evans $(\bowtie) \cdot$ P. Whelehan · K. Thomson - C. A. Purdie

L. B. Jordan - C. O. Michie - A. Thompson - S. Vinnicombe

Dundee Cancer Centre, Ninewells Hospital \& Medical School,

Mailbox 4, Dundee DD1 9SY, UK

e-mail: a.z.evans@dundee.ac.uk

P. Rauchhaus

Division of Population Health Sciences, Ninewells Hospital \&

Medical School, Dundee DD1 9SY, UK with a mean stiffness of $>150 \mathrm{kPa}$. At multivariate analysis, invasive size, tumour type, vascular invasion, and mean stiffness maintained independent significance. Mean stiffness at SWE is an independent predictor of lymph node metastasis and thus can confer prognostic information additional to that provided by conventional preoperative tumour assessment and staging.

Keywords Breast cancer · Prognosis · Elastography · Metastasis

\section{Introduction}

Several large studies have shown that the addition of shear wave elastography (SWE) to greyscale ultrasound improves the performance of ultrasound examination in differentiating benign from malignant breast masses [1-3]. SWE is quantitative and highly reproducible, in contrast to static elastography [3-6]. The combination of SWE and greyscale ultrasound has been shown to be highly sensitive; that is, if both are negative, malignancy is extremely unlikely (no false-negative cases in a series of 111 published in 2012) [3]. It is therefore likely that SWE will be increasingly used in routine clinical practise.

It has been shown that large invasive size, high histological grade and vascular invasion are independently associated with increased stiffness at SWE [7, 8]. These studies did not show lesion stiffness to be an independent predictor of nodal status but given the relatively small numbers, they may have been underpowered for this outcome. Lymph node status is the most powerful prognostic indicator in breast cancer [9] and knowledge of lymph node status influences both surgical management and the use of systemic therapy (adjuvant and neoadjuvant). 
More accurate identification of likely lymph node metastases at diagnosis could minimise the need for a subsequent surgical procedure to clear the axilla following initial surgery and sentinel node biopsy. A second operation carries costs and risks, in addition to an inevitable delay in time to initiation of adjuvant chemotherapy, which should be given in a timely fashion to optimise long-term patient outcome [10].

The aim of this study was to determine, in a large series of patients with primary invasive breast cancer treated initially by surgery, whether SWE findings could independently predict lymph node status when taking known predictors of nodal status such as invasive size, histological grade and vascular invasion status [11, 12] into account. If SWE finding are predictive of lymph node involvement this may be clinically useful in selecting patients for neoadjuvant chemotherapy (NACT), as the established predictors of nodal involvement are only definitively available post operatively, and ultrasound guided percutaneous biopsy of nodes with abnormal ultrasound morphology only establishes a diagnosis of nodal metastases in around $50 \%$ of cases shown to be positive at surgery [13].

\section{Patients and methods}

SWE has been part of routine breast ultrasound examinations at our institution since November 2009. In accordance with the applicable UK National Research Ethics Service guidance [14], ethical approval for the study was not required. Consecutive patients with invasive breast cancer identified during ultrasound scans using the Aixplorer ${ }^{\circledR}$ ultrasound system (SuperSonic Imagine, Aix en Provence, France) between 19/04/2010 and 12/12/2012 and treated by primary surgery were included in this study.

The sample included women with symptoms and women with screen-detected abnormalities. All women were scanned and biopsied by one of three breast radiologists or an advanced radiography practitioner trained to perform and interpret breast ultrasonography. These practitioners had between 5 and 20 years of breast ultrasound experience and had at least 3 months experience of performing SWE of solid breast lesions.

Greyscale and elastography images were obtained during the standard ultrasound appointment. The elastography colour map findings were taken into account in the diagnostic management of the patients but the quantitative measurements were produced and analysed later to minimise impact on workflow. The elasticity values were obtained by moving a delineated region of interest (ROI) over the colour map. As the ROI moves, the readings change in real time so the ROI can be positioned over the part of the image showing the stiffest tissue.
Four elastography images - in each of two orthogonal planes-were taken of each lesion. The transducer was held still over the lesion for about $10 \mathrm{~s}$ to allow the shear wave image to build up. If the patient was breathing heavily, she was asked to hold her breath during acquisition. Mean ROI stiffness values $(\mathrm{kPa})$ from the four images were used for analysis.

Analysis was based on histological data points from pathological examination of the resected specimen: histological grade, tumour type, invasive size, vascular invasion, ER, HER-2 status and lymph node stage. These were assessed according to UK national guidelines [15, 16]. Macro-metastases were counted as node positive while micro-metastases and isolated tumour cells were counted as node negative. Univariate and multivariate logistic regression were used to establish the significance of associations of histological and shear wave findings with lymph node status.

\section{Results}

The sample comprised 396 patients; 217 presented with symptoms, whereas 179 had cancers detected by mammographic screening. The patients' ages ranged from 31 to 92 years with a median of 62 years. The histological characteristics of the study group are shown in Table 1. The median invasive tumour size was $19 \mathrm{~mm}, 28 \%$ of patients had lymph node metastases and $27 \%$ had vascular invasion. The tumour stiffness values according to nodal status are shown in Table 2. Nodal status according to range of mean stiffness values is shown in Table 3. Nodal metastasis rates ranged from $7 \%$ for tumours with mean stiffness $<50 \mathrm{kPa}$ to $41 \%$ for tumours with a mean stiffness of $>150 \mathrm{kPa}$.

At univariate analysis, invasive size, histological grade, HER-2 status, vascular invasion, tumour type and mean

Table 1 Histological features of the 396 invasive cancers in the study group

\begin{tabular}{llc} 
& Grade 1 & $55(14)$ \\
& Grade 2 & $167(42)$ \\
& Grade 3 & $174(44)$ \\
& Node positive & $112(28)$ \\
& Vascular invasion & $105(27)$ \\
& HER 2 positive ${ }^{\mathrm{a}}$ & $36(9)$ \\
& ER positive & $330(83)$ \\
& PR positive & $271(68)$ \\
& Invasive size & $131(33)$ \\
a 6 patients had unknown HER & $<15$ mm & \\
\cline { 2 - 3 } 2 status &
\end{tabular}


Table 2 Mean stiffness (kPa) values of 396 breast cancers by nodal status

\begin{tabular}{llll}
\hline & $\begin{array}{l}\text { Range of mean } \\
\text { stiffness values } \\
(\mathrm{kPa})\end{array}$ & $\begin{array}{l}\text { Mean of mean } \\
\text { stiffness values } \\
(\mathrm{kPa})\end{array}$ & $\begin{array}{l}\text { Median of mean } \\
\text { stiffness values } \\
(\mathrm{kPa})\end{array}$ \\
\hline $\begin{array}{c}\text { Node negative } \\
(n=284)\end{array}$ & $14-281$ & 114 & 105 \\
$\begin{array}{c}1-3 \text { nodes } \\
\text { positive } \\
(n=78)\end{array}$ & $31-281$ & 141 & 130 \\
$\begin{array}{l}4 \text { or more } \\
\text { nodes } \\
\text { positive } \\
(n=34)\end{array}$ & $77-265$ & 156 & \\
\hline
\end{tabular}

Table 3 Nodal status according to mean stiffness value (range)

\begin{tabular}{lcc}
\hline $\begin{array}{l}\text { Mean stiffness } \\
\text { range }(\mathrm{kPa})\end{array}$ & $\begin{array}{l}\text { Node negative } \\
n(\%)\end{array}$ & $\begin{array}{l}\text { Node positive } \\
n(\%)\end{array}$ \\
\hline$<50$ & $27(93)$ & $2(7)$ \\
$50-99$ & $101(78)$ & $28(22)$ \\
$100-149$ & $83(72)$ & $32(28)$ \\
$>150$ & $73(59)$ & $50(41)$ \\
\hline
\end{tabular}

stiffness were significantly associated with nodal involvement while ER, PR and age were not (Table 4). At multivariate analysis, invasive size, tumour type, vascular invasion and mean stiffness maintained independent significance in predicting nodal involvement while ER, PR, HER-2, age and histological grade did not (Table 5).

\section{Discussion}

We have found that mean stiffness as measured by SWE is an independent predictor for nodal involvement in breast cancer in addition to well-established predictors such as invasive size and vascular invasion status. In contrast to previous studies, [11, 12] histological grade was not an independent predictor of nodal involvement on multivariate analysis. This may be because stiffness on SWE is associated with histological grade $[7,8]$.

The stiff tissue associated with invasive breast cancer is usually seen at the periphery of the tumour, extending into the peri-tumoural stroma. Often, the tumour itself is less stiff than the surrounding stroma. Although not proven, it is likely that the stiffness represents abnormal tumour-associated collagen, which has been shown to exhibit increased collagen crosslinking and abnormal alignment. These collagen abnormalities have recently been shown to have independent prognostic significance [17, 18]. In recent years, stromal gene signatures, and components such as
Table 4 Univariate logistic regression

\begin{tabular}{llr}
\hline Dependent parameter & Independent parameter & $p$ value \\
\hline Nodal Involvement (yes/no) & Age (years) & 0.6083 \\
& ER (binary) & 0.1739 \\
& HER2 status & 0.0408 \\
& Invasive size (mm) & $<0.0001$ \\
& PR (binary) & 0.0930 \\
& Stiffness reading & $<0.0001$ \\
& Tumour grade & $<0.0001$ \\
& Tumour type (classified) & 0.0020 \\
& Vascular invasion & $<0.0001$ \\
\hline
\end{tabular}

Table 5 Multivariate logistic regression

\begin{tabular}{llr}
\hline Dependent parameter & Independent parameter & $p$ value \\
\hline Nodal involvement (yes/no) & Age (years) & 0.7655 \\
& ER (binary) & 0.4626 \\
& HER2 status & 0.4570 \\
& Invasive size (mm) & $<0.0001$ \\
& PR (binary) & 0.3698 \\
& Stiffness reading & 0.0350 \\
& Tumour grade & 0.6300 \\
& Tumour type (classified) & 0.0104 \\
& Vascular invasion & 0.0027 \\
\hline
\end{tabular}

Caveolin 1 and LOX 2, have been shown to be important prognostic and predictive indicators in breast cancer [1922]. It is possible that the peri-tumoural stromal stiffness represents an imaging surrogate for some of these stromal processes. As these stromal prognostic indicators are not measured by the conventional predictors of nodal involvement, such as invasive size and histological grade, it is not surprising that stromal stiffness has independent predictive significance. Vascular invasion, another wellestablished predictive factor for axillary lymph node metastasis in breast cancer, has been shown to have a strong relationship with stromal stiffness on SWE [7, 8]. Like SWE stiffness, vascular invasion is also most commonly seen at the tumour-stromal interface [23]. The independence of vascular invasion and stromal stiffness as predictors of nodal metastasis suggests that the predictive power of stromal stiffness is mediated by other factors in addition to vascular invasion.

Previous SWE studies have found that increased stiffness is associated with nodal metastases on univariate analysis $[7,8]$. However, these studies did not show SWE stiffness to be an independent predictor of lymph node metastasis on multivariate analysis. This difference in findings compared to the current study may reflect insufficient statistical power resulting from the lower participant 
numbers (166 and 100, compared to 396 in this study). The larger of the previous studies took only one shear wave measurement from each tumour while the current study took four, further increasing the statistical power of our study.

The main weakness of the current study is that it is from a single centre with a special interest in SWE. We do not know whether such results are reproducible in other clinical centres. Although the analysis was retrospective, the SWE data were acquired prospectively as part of our routine clinical practise, and recorded before core biopsy results or surgical pathology were known.

In current practise, ultrasound guided needle biopsy of axillary lymph nodes with abnormal cortical morphology allows pre-operative diagnosis of axillary metastases in only around $50 \%$ of women [13]. Preoperative diagnosis of nodal metastases is valuable as, when added to tumour size estimation on imaging and histological grading on core biopsy, it refines preoperative prognostication [24, 25]. This can facilitate the use of NACT to down-stage tumours prior to surgery, or to identify more accurately at diagnosis the most appropriate axillary surgery for patients following NACT. There remains some debate regarding the optimal timing of sentinel lymph node biopsy (SLNB) in patients receiving NACT [26], and the false negative rate of SLNB after neoadjuvant chemotherapy may be higher than would be deemed acceptable [27]; consequently, any tool to help facilitate more accurate staging of the axilla at diagnosis would be valuable. Our findings suggest that SWE has the potential to refine preoperative prognostication, and thus help improve decision making with regard to neo-adjuvant chemotherapy and management of the axilla.

In conclusion, mean stiffness at SWE is an independent predictor of lymph node metastasis in women with invasive breast cancer and thus can contribute additional, noninvasive prognostic information compared to conventional preoperative tumour assessment and staging.

Acknowledgments This work was part funded by EPSRC grant EP/ K020439/1. SuperSonic Imagine has part-funded a PhD studentship in the authors' institution. This work does not form part of that studentship and the company has had no input into the work.

Conflict of interest The authors declare no other potential conflict of interest.

Ethical Standards In accordance with the applicable UK National Research Ethics Service guidance [14], ethical approval for the study was not required.

\section{References}

1. Berg WA, Cosgrove DO, Dore CJ, Schaefer FKW, Svensson WE, Hooley RJ, Ohlinger R, Mendelson EB, Balu-Maestro C,
Locatelli M, Tourasse C, Cavanaugh BC, Juhan V, Stavros AT, Tardivon A, Gay J, Henry JP, Cohen-Bacrie C (2012) Shear-wave elastography improves the specificity of breast US: the BE1 multinational study of 939 masses. Radiology 262(2):435-449

2. Chang JM, Moon WK, Cho N, Yi A, Koo HR, Han W, Noh DY, Moon HG, Kim SJ (2011) Clinical application of shear wave elastography (SWE) in the diagnosis of benign and malignant breast diseases. Breast Cancer Res Treat 129(1):89-97

3. Evans A, Whelehan P, Thomson K, Brauer K, Jordan L, Purdie C, McLean D, Baker L, Vinnicombe S, Thompson A (2012) Differentiating benign from malignant solid breast masses: value of shear wave elastography according to lesion stiffness combined with greyscale ultrasound according to BI-RADS classification. Br J Cancer 107(2):224-229

4. Regner D, Hesley G, Hangiandreou N, Morton M, Nordland M, Meixner D, Hall T, Farrell M, Mandrekar J, Harmsen W, Charboneau J (2006) Breast lesions: evaluation with US strain imaging-clinical experience of multiple observers. Radiology 238:425-437

5. Burnside ES, Hall TJ, Sommer AM, Hesley GK, Sisney GA, Svensson WE, Fine JP, Jiang J, Hangiandreou NJ (2007) Differentiating benign from malignant solid breast masses with US strain imaging. Radiology 245(2):401-410

6. Cosgrove DO, Berg WA, Dore CJ, Skyba DM, Henry JP, Gay J, Cohen-Bacrie C (2012) Shear wave elastography for breast masses is highly reproducible. Eur Radiol 22(5):1023-1032

7. Youk JH, Gweon HM, Son EJ, Kim JA, Jeong J (2013) Shearwave elastography of invasive breast cancer: correlation between quantitative mean elasticity value and immunohistochemical profile. Breast Cancer Res Treat 138(1):119-126

8. Evans A, Whelehan P, Thomson K, McLean D, Brauer K, Purdie C, Baker L, Jordan L, Rauchhaus P, Thompson A (2012) Invasive breast cancer: relationship between shear-wave elastographic findings and histologic prognostic factors. Radiology 263(3):673-677

9. Fitzgibbons PL, Page DL, Weaver D, Thor AD, Craig Allred D, Clark GM, Ruby SG, O'Malley F, Simpson JF, Connolly JL, Hayes DF, Edge SB, Lichter A, Schnitt SJ (2000) Prognostic factors in breast cancer. Arch Pathol Lab Med 124(7):966-978

10. Vandergrift JL, Niland JC, Theriault RL, Edge SB, Wong YN, Loftus LS, Breslin TM, Hudis CA, Javid SH, Rugo HS, Silver SM, Lepisto EM, Weeks JC (2013) Time to adjuvant chemotherapy for breast cancer in national comprehensive cancer network institutions. J Natl Cancer Inst 105(2):104-112

11. Bevilacqua JLB, Kattan MW, Fey JV, Cody Iii HS, Borgen PI, Van Zee KJ (2007) Doctor, what are my chances of having a positive sentinel node? A validated nomogram for risk estimation. J Clin Oncol 25(24):3670-3679

12. Qiu PF, Liu JJ, Wang YS, Yang GR, Liu YB, Sun X, Wang CJ, Zhang ZP (2012) Risk factors for sentinel lymph node metastasis and validation study of the MSKCC nomogram in breast cancer patients. Jpn J Clin Oncol 42(11):1002-1007

13. Houssami N, Ciatto S, Turner RM, Cody HS, MacAskill P (2011) Preoperative ultrasound-guided needle biopsy of axillary nodes in invasive breast cancer: meta-analysis of its accuracy and utility in staging the axilla. Ann Surg 254(2):243-251

14. National Research Ethics Service (2008) Approval for medical devices research: guidance for researchers, manufacturers, research ethics committees and NHS R\&D offices (Version 2). National Patient Safety Agency, London

15. Guidelines working group of the national coordinating committee for breast pathology (2005) Pathology reporting of breast disease (NHSBSP publication 58). NHS Cancer Screening Programmes $\&$ The Royal College of Pathologists, London

16. Purdie CA, Jordan LB, McCullough JB, Edwards SL, Cunningham J, Walsh M, Grant A, Pratt N, Thompson AM (2010) HER2 
assessment on core biopsy specimens using monoclonal antibody CB11 accurately determines HER2 status in breast carcinoma. Histopathology 56(6):702-707

17. Conklin MW, Eickhoff JC, Riching KM, Pehlke CA, Eliceiri KW, Provenzano PP, Friedl A, Keely PJ (2011) Aligned collagen is a prognostic signature for survival in human breast carcinoma. Am J Pathol 178(3):1221-1232

18. Levental KR, Yu H, Kass L, Lakins JN, Egeblad M, Erler JT, Fong SFT, Csiszar K, Giaccia A, Weninger W, Yamauchi M, Gasser DL, Weaver VM (2009) Matrix crosslinking forces tumor progression by enhancing integrin signaling. Cell 139(5):891-906

19. Chen LC, Tu SH, Huang CS, Chen CS, Ho CT, Lin HW, Lee CH, Chang HW, Chang CH, Wu CH, Lee WS, Ho YS (2012) Human breast cancer cell metastasis is attenuated by lysyl oxidase inhibitors through down-regulation of focal adhesion kinase and the paxillin-signaling pathway. Breast Cancer Research Treat. doi:10.1007/s10549-012-1986-8

20. Farmer P, Bonnefoi H, Anderle P, Cameron D, Wirapati $P$, Becette V, Andr ̃̃ $\odot$ S, Piccart M, Campone M, Brain E, MacGrogan G, Petit T, Jassem J, Bibeau F, Blot E, Bogaerts J, Aguet M, Bergh J, Iggo R, Delorenzi M (2009) A stroma-related gene signature predicts resistance to neoadjuvant chemotherapy in breast cancer. Nat Med 15(1):68-74

21. Witkiewicz AK, Dasgupta A, Sotgia F, Mercier I, Pestell RG, Sabel M, Kleer CG, Brody JR, Lisanti MP (2009) An absence of stromal caveolin-1 expression predicts early tumor recurrence and poor clinical outcome in human breast cancers. Am J Pathol 174(6):2023-2034

22. Hatzis C, Pusztai L, Valero V, Booser DJ, Esserman L, Lluch A, Vidaurre T, Holmes F, Souchon E, Wang H, Martin M, Cotrina J, Gomez H, Hubbard R, ChacÃn JI, Ferrer-Lozano J, Dyer R, Buxton M, Gong Y, Wu Y, Ibrahim N, Andreopoulou E, Ueno
NT, Hunt K, Yang W, Nazario A, DeMichele A, O'Shaughnessy J, Hortobagyi GN, Symmans WF (2011) A genomic predictor of response and survival following taxane-anthracycline chemotherapy for invasive breast cancer. JAMA 305(18):1873-1881

23. Kandemir NO, Barut F, Bektas S, Ozdamar SO (2012) Can lymphatic vascular density be used in determining metastatic spreading potential of tumor in invasive ductal carcinomas? Pathol Oncol Res 18(2):253-262

24. Kwok TC, Rakha EA, Lee AHS, Grainge M, Green AR, Ellis IO, Powe DG (2010) Histological grading of breast cancer on needle core biopsy: the role of immunohistochemical assessment of proliferation. Histopathology 57(2):212-219

25. O'Shea AM, Rakha EA, Hodi Z, Ellis IO, Lee AHS (2011) Histological grade of invasive carcinoma of the breast assessed on needle core biopsy-modifications to mitotic count assessment to improve agreement with surgical specimens. Histopathology 59(3):543-548

26. Boughey J, Suman V, Mittendorf E, Ahrendt G, Wilke L, Taback B, Leitch A, Flippo-Morton T, Byrd D, Ollila D, Julian T, McLaughlin S, McCall L, Symmans W, Le-Petross H, Haffty B, Buchholz T (2012) The role of sentinel lymph node surgery in patients presenting with node positive breast cancer (T0-T4, N1-2) who receive neoadjuvant chemotherapy-results from the ACOSOG Z1071 trial. Cancer Res 72((24 Suppl.)):Abstract nr S2-1

27. Kuehn T, Bauerfeind I, Fehm T, Fleige B, Helms G, Lebeau A, Liedtke C, von Minckwitz G, Nekljudova V, Schrenk P, Staebler A, Untch M (2012) Sentinel lymph node biopsy before or after neoadjuvant chemotherapy - final results from the prospective German, multiinstitutional SENTINA-trial. Cancer Res 72((24 Suppl.)):Abstract nr S2-2 